\title{
Safety of endoscopic retrograde cholangiopancreatography in patients 80 years of age and older
}

\author{
Baydar Behlül ${ }^{1}$, Serin Ayfer², Vatansever Sezgin³, Kandemir Altay ${ }^{3}$, Çelik Mustafa ${ }^{3}$, Çekiç Cem³ ${ }^{3}$ Örmeci Bilge ${ }^{4}$, \\ Aslan Fatih ${ }^{3}$, Alper Emrah³, Buyraç Zafer ${ }^{5}$, Aksöz Kadir ${ }^{6}$, Ünsal Belkis ${ }^{3}$ \\ 'Department of Surgical Gastroenterology, Tekden Hospital, Bağcılar, Istanbul, Turkey \\ 2Department of Gastroenterology, Ege University, Bornova, Izmir, Turkey \\ ${ }^{3}$ Department of Gastroenterology, Katip Çelebi University, Izmir, Turkey \\ ${ }^{4}$ Department of Gastroenterology, Atatürk Government Hospital, Antalya, Turkey \\ IIGEM Gastroenterology Center, Izmir, Turkey \\ ${ }^{6}$ Department of Gastroenterology, Şifa University, İzmir, Turkey
}

Prz Gastroenterol 2014; 9 (4): 227-231

DOI: $10.5114 / p g .2014 .45105$

Key words: endoscopic retrograde cholangiopancreatography, indications, elderly, safety.

Address for correspondence: Ayfer Serin, Department of Gastroenterology, Ege University, Bornova, 35100 Izmir, Turkey, phone: 0903905193, fax: 0902323427764, e-mail: ayferserin@gmail.com

\begin{abstract}
Introduction: Endoscopic retrograde cholangiopancreatography (ERCP) is used in the diagnosis and therapy of biliary tract diseases. The ERCP is an invasive procedure that does not increase complications in the elderly. Few studies have assessed the safety of ERCP in the elderly. Life expectancy is rising, which causes an increasing demand for ERCP in the elderly.

Aim: To show that therapeutic ERCP is safe and we compared the level of complications among the elderly $(>80$ years of age) and the level among a younger group ( $<65$ years of age).

Material and methods: The study was designed retrospectively. The details of all patients 80 years of age and older undergoing ERCP were analysed. One hundred and fifty patients were included in each of the groups: $>80$ years of age, older group A; and $<65$ years of age, younger group B.

Results: In group A, 4 cases (2.7\%) of bleeding (all mild) was observed, and perforation was not observed. The ERCP-related mild pancreatitis was observed in 7 patients (4.6\%). There were no cases of mortality during procedures of ERCP in group A. In group B 6 bleeding cases (4\%) (all mild) were observed. Perforation was not observed in group B. ERCP-related mild pancreatitis occurred in 11 patients (7.3\%). There were no cases of mortality during procedures of ERCP in group B. Our study showed that ERCP is a safe and effective procedure in elderly patients.

Conclusions: Outcomes of ERCP for diagnostic and therapeutic success, and complication rates, are similar to those in younger patients. The ERCP is effective and safe in the elderly.
\end{abstract}

\section{Introduction}

Endoscopic retrograde cholangiopancreatography $(E R C P)$ is used in the diagnosis and therapy of biliary tract diseases. There are complications of ERCP such as gastrointestinal haemorrhage, perforation, acute pancreatitis, allergy to contrast media, or adverse effect of drugs administered during anaesthesia. Life expectancy is rising, with a corresponding increase in demand for ERCP in the elderly. Although procedural complications are not age related, it is related to comorbidity in elder- ly patients [1]. The ERCP is an invasive procedure that does not increase its complications in the elderly. Few studies have assessed the safety of ERCP in the elderly [2-4]. We retrospectively compared the characteristics and outcomes of patients undergoing ERCP.

\footnotetext{
Aim

The aim of this study is to show that therapeutic ERCP is safe and that the complication rates are comparable between the elderly ( $>80$ years of age) and the younger group ( $<65$ years of age).
} 


\section{Material and methods}

The study involved a total of 300 patients undergoing diagnostic and therapeutic ERCP at Katip Çelebi University Hospital in Izmir between 2008 and 2009. Among them, 150 patients were 80 years of age and older (group A) and 150 patients were less than 65 years old (group B). Between January 2008 and August 2009, 1785 ERCPs were performed in our hospital. All patients were investigated with non-invasive techniques, including ultrasonography, computed tomography (CT), and magnetic resonance cholangiopancreatography (MRCP), before the ERCP procedure. A retrospective study of patient records from a single tertiary care hospital was performed. Patient demographics and diagnosis, blood results, indications of ERCP, results and complications of ERCP, and postprocedure outcomes were recorded. Details of all patients 80 years of age and older undergoing ERCP were analysed from an endoscopy database of medical notes. One hundred and fifty patients were included in the older group (group A) and 150 patients were in the younger group (group B).

\section{Statistical analysis}

The $\chi^{2}$ test and Student's $t$-test were used for statistical comparison. Differences were taken as significant when $p<0.05$. We compared the indications, interventions, and complications of ERCP of group A with those of group $B$.

\section{Results}

The study involved a total 300 patients undergoing diagnostic and therapeutic ERCP in hospital; among them, 150 patients were 80 years of age and older and 150 patients were less than 65 years old. The elderly group consisted of 91 women and 59 men; a total of 150 patients (group A) with a mean age of $84.6 \pm 3.2$ years. There were 150 patients in the younger group (group B), 85 women and 65 men, with a median age of $50.3 \pm 15.3$ years. One hundred and eighty-eight ERCP procedures were performed in group A, and 205 ERCP procedures were performed in group $B$. All patients were sedated using intravenous drug administration.
The procedures were postponed in only 2 of the patients because of hypoxia and bradycardia in group $A$.

Indications for ERCP in group A were as follows: obstructive jaundice 138 (92\%), biliary leak 1 (0.6\%), choledocholithiasis (70.6\%), and malignant biliary stenosis 32 (21.3\%).

Indications for ERCP in group B were as follows: obstructive jaundice 138 (92\%), biliary leak 3 (2\%), choledocholithiasis 120 (80\%), and malignant biliary stenosis 18 (12\%).

Malignant biliary stenosis was seen in 32 (21.3\%) in group A and in 18 (12\%) in group B. This difference was taken as significant $(p<0.05)$. The ERCP indications are shown in Table I. In both groups choledocholithiasis was the most frequent diagnosis, but which, when compared between group $A$ and group $B$, was not significant.

Successful cannulation of the common bile duct (CBD) was achieved $98.6 \%$ of patients in group A. Endoscopic sphincterotomy and balloon fishing were performed in a total of 134 (89.3\%) patients in group A. Basket extraction was performed in 15 (10\%) of these patients because of large stones, and biliary stents were placed in $7(4 \%)$ patients because of malignant aetiologies. The ERCP interventions in patients are shown in Table II.

Successful cannulation of the CBD was achieved in 146 patients (97.3\%) in group B. Total endoscopic sphincterotomy and balloon fishing were performed in 140 patients (93.3\%), basket extraction was performed $4(2 \%)$ of these patients, and biliary stents were placed in $6(4 \%)$ patients because of malignant aetiologies (Table II).

Endoscopic sphincterotomy and balloon fishing and basket extraction were more common interventional procedures in group $A-15$ patients (10\%) than in group $\mathrm{B}-4$ patients (2\%), $p<0.05$.

Complications of ERCP in group A were as follows: 4 bleeding (2.7\%) (all mild) and 7 (4.6\%); ERCP-related mild pancreatitis cases were observed; and perforation was not observed; length of hospital stay was 6.5 \pm 2 days (1-60 days); there was no ERP-related mortality. The complications of ERCP in our study are shown in Table III.

Table I. Indications for ERCP in patients

\begin{tabular}{lccc} 
Indication & $\begin{array}{c}\text { Group A }(\boldsymbol{N}=150) \\
n(\%)\end{array}$ & $\begin{array}{c}\text { Group B }(\boldsymbol{N}=150) \\
n(\%)\end{array}$ & Value of $p$ \\
\hline Obstructive jaundice & $138(92)$ & $138(92)$ & $>0.05$ \\
\hline Malign biliary stenosis & $32(21.3)$ & $18(12)$ & $>0.05$ \\
\hline Choledocholithiasis & $106(70.6)$ & $3(2)$ & $>0.05$ \\
\hline Biliary leak & $1(0.6)$ & $30)$ & $>05$
\end{tabular}

Student's t-test and the $\chi^{2}$ test 
Table II. The Interventions of ERCP in patients

\begin{tabular}{lccc} 
ERCP procedures & $\begin{array}{c}\text { Group A } \\
n(\%)\end{array}$ & $\begin{array}{c}\text { Group B } \\
n(\%)\end{array}$ & Value of $p$ \\
\hline Successful ERCP & $148(98.6)$ & $146(97.3)$ & $>0.05$ \\
\hline Endoscopic sphincterotomy and balloon & $134(89.3)$ & $140(93)$ & $>0.05$ \\
\hline Endoscopic sphincterotomy and balloon and basket & $15(10)$ & $4(2)$ & $<0.05$ \\
\hline Endoscopic sphincterotomy and balloon and biliary stent & $7(4)$ & $6(4)$ & $>0.05$
\end{tabular}

Student's t-test and the $\chi^{2}$ test

Table III. Complication of ERCP in patients

\begin{tabular}{|c|c|c|c|}
\hline Complication & $\begin{array}{c}\text { Group A } \\
n(\%)\end{array}$ & $\begin{array}{c}\text { Group B } \\
n(\%)\end{array}$ & Value of $p$ \\
\hline Bleeding & $4(2.7)$ & $6(4)$ & $>0.05$ \\
\hline Perforation & $0(0)$ & $0(0)$ & $>0.05$ \\
\hline Mortality & $0(0)$ & $0(0)$ & $>0.05$ \\
\hline Hypoxia & $2(1)$ & $0(0)$ & $<0.05$ \\
\hline Pancreatitis (mild) & $7(4.6)$ & $11(7.3)$ & $<0.05$ \\
\hline
\end{tabular}

Student's t-test and the $\chi^{2}$ test

Table IV. Distribution of malignant biliary stenosis in patients

\begin{tabular}{|c|c|c|c|}
\hline Malignant biliary stenosis & $\begin{array}{c}\text { Group A } \\
n(\%)\end{array}$ & $\begin{array}{c}\text { Group B } \\
n(\%)\end{array}$ & Value of $p$ \\
\hline Pancreatic carcinoma & $18(56.3)$ & $7(38.8)$ & $<0.05$ \\
\hline Cholangiocarcinoma & $6(18.7)$ & $4(22.3)$ & $>0.05$ \\
\hline Malignant compression of the common bile duct & $3(9.4)$ & $4(22.3)$ & $>0.05$ \\
\hline Carcinoma of the ampulla & $5(15.6)$ & $3(16.6)$ & $>0.05$ \\
\hline Total & 32 & 18 & $<0.05$ \\
\hline
\end{tabular}

Student's t-test and the $\chi^{2}$ test

Complications of ERCP in group B were as follows: 6 bleeding (4\%) (all mild) were observed; ERCP-related mild pancreatitis, which occurred in 11 patients (7.3\%); length of hospital stay was $5.5 \pm 2$ days (1-60 days); 114 ERCP procedures (76\%) were performed in outpatients; there was no ERCP-related mortality; and perforation was not observed (Table III).

The most frequent complication was mild pancreatitis, which was significantly more developed in young patients than in older patients $(7.3 \%$ vs. $4.6 \%, p<0.05)$.

All patients were sedated using intravenous anaesthesia. The ERCP procedures were delayed in just 2 patients in group A because they had hypoxia during sedation, and in group B there was no hypoxia from the anaesthesia.

In both groups, choledocholithiasis was the most frequent diagnosis: $70.6 \%$ and $80 \%$ group $A$ and group $B$, respectively. Malignant biliary stenosis was more common in group A $(21.3 \%)$ than in group B $(12 \%)$ $(p<0.05)$.
In group A, among the malignant aetiologies (36 patients) shown in Table IV, pancreatic carcinoma was the most frequent cancer 18 (56.3\%), followed by 6 (18.7\%) cholangiocarcinoma, 3 (9.4\%) malignant mass compression of the common bile duct, and 5 (13.5\%) carcinoma of the ampulla.

In group $\mathrm{B}$, among the malignant aetiologies (18 patients), 7 (38.8\%) were pancreatic carcinoma, 4 (22.3\%) were cholangiocarcinoma, 4 (22.3\%) were malignant mass compression of the common bile duct, and 3 (16.6\%) were carcinoma of the ampulla (shown in Table IV).

\section{Discussion}

Therapeutic ERCP has been accepted for the treatment of choledocholithiasis in elderly patients with concomitant diseases [5-8]. There have been several reports on the results of therapeutic ERCP for the elderly. We proved the efficacy and safety of therapeutic ERCP for choledocholithiasis in patients 80 years 
of age and older in our study. Total complications of ERCP were $6.5 \%$ and $11 \%$ in group $A$ and group B, respectively. These results are similar to those of previous studies (from 6.3 to 11.0) [4, 9-12]. Post-procedure mild pancreatitis was observed $4.6 \%$ of patients in group $A$ and in $7.3 \%$ in group B. There was an increase in post-procedure mild pancreatitis in group B $(7.3 \%$ vs. $4.6 \% ; p<0.05)$. The procedure-related mortality rate was given as $0.7 \%$ by some other studies [13]. In our study, procedure-related death was not observed and severe pancreatitis did not occur.

In our study successful cannulation of the CBD was achieved in $98.6 \%$ in group $A$ and in $97.3 \%$ in group B. Achievement of cannulation of CBD was similar in group $A$ and in group $B$, and this is not significant. In our study, we found that elderly patients who underwent ERCP presented more frequent malignant biliary diseases than did younger patients $(p<0.05)$. Bleeding was observed $2.7 \%$ in group $A$ and $4 \%$ in group B. Perforation was not observed in either group. Hypoxia occured in 1 patient and bradycardia occurred in 1 patient during sedation in group A. Hypoxia occurred only in two patients during sedation in group B. Complications related to sedation were similar in group $A$ and in group $B$. The results of this study assessed the complications of ERCP in which there is no significant difference demonstrated between elderly and younger patients. Post-ERCP complications were frequently minor and comparable in the younger and older patients, except for pancreatitis, which was more prevalent in the younger group. Our study showed that ERCP is a safe and effective procedure in elderly patients.

There have been a few studies recently that have reported their experience of ERCP in the elderly (> 80 years old) population [12-17]. The first of these studies was by Köklü et al. They showed that therapeutic ERCP is safe, and they compared the complication rates between the elderly ( $>70$ years old) and the younger group [18]. In our study we reported our own experience of ERCP in the elderly (> 80 years) population. We also showed that ERCP in elderly patients is safe.

Another study was by Chong et al. [19]. They also showed that ERCP in the elderly ( $>80$ years) is safe. However, complications were seen, and these were mainly related to sedation, but no significant difference was seen between the older and younger groups in this study. Similar complications such as bradycardia and hypoxia were seen in our study.

In addition, MacMahon et al. studied ERCP in 50 elderly patients, aged between 65 and 94 years, and examined its safety and therapeutic effectiveness [20]. They found that ERCP was successful in 46 out of
50 (92\%) procedures. There were no major complications recorded in this study. In our study we also concluded that ERCP was effective and safe in elderly patients, and showed that there were no severe complications in our study.

\section{Conclusions}

The ERCP is an effective and safe procedure in elderly patients. Outcomes of ERCP for diagnostic and therapeutic success, and complication rates, are similar to those seen in younger patients.

\section{References}

1. Ertuğrul I, Yüksel I, Parlak E, et al. Risk factors for endoscopic retrograde cholangiopancreatography-related cholangitis: a prospective study. Turk J Gastroenterol 2009; 20: 116-21.

2. Talar-Wojnarowska R, Sculc G, Wozniak B, et al. Assessment of frequency and safety of endoscopic retrograde cholangiopancreatography in patient over 80 years of age. Pol Arch Med Wewn 2009; 119: 136-40.

3. Lukens FJ, Howell DA, Upender S, et al. ERCP in the very elderly: outcomes among patients older than eighty. Dig Dis Sci 2010; 55: 847-51.

4. Murata A, Motomura Y, Akahoshi K, et al. Therapeutic ERCP for choledocholithiasis in patients 80 years of age and older. J Clin Gastroenterol 2009; 43: 289-90.

5. Affronti J. Biliary disease in the elderly patient. Clin Geriatr Med 1999; 15: 571-8.

6. Lygidakis NJ. Operative risk factors of cholecystectomy-choledochotomy in the elderly. Surg Gynecol Obstet 1983; 157: 15-9.

7. Sieguel JH, Kasmin FE. Biliary tract diseases in the elderly: management and outcomes. Gut 1997; 41: 433-5.

8. Gonzalez JJ, Sanz L, Grana JL, et al. Biliary lithiasis in the elderly patient: morbidity and mortality due to biliary surgery. Hepatogastroenterology 1997; 44: 1565-8.

9. Fritz E, Kirchgatterer A, Hubner D, et al. ERCP is safe and effective in patients 80 years of age and older compared with younger patients. Gastrointest Endosc 2006; 64: 899-905.

10. Katsinelos P, Paroutoglou G, Kountouras J, et al. Efficacy and safety of therapeutic ERCP in patients 90 years of age and older. Gastrointest Endosc 2006; 63: 417-23.

11. Freeman ML, Nelson DB, Sherman S, et al. Complications of endoscopic biliary sphincterotomy. N Engl J Med 1996; 335: 909-18.

12. Thomopoulos KC, Vagenas K, Assimakopoulos SF, et al. Endoscopic retrogade cholangiopancreatography is safe and effective method for diagnosis and treatment of biliary and pancreatic disorders in octogenarians. Acta Gastroenterol Belg 2007; 70: 199-202.

13. Rodríguez-González FJ, Naranjo-Rodríguez A, Mata-Tapia I, et al. ERCP in patients 90 years of age and older. Gastrointest Endosc 2003; 58: 220-5.

14. Ito Y, Tsujino T, Togawa O, et al. Endoscopic papillary balloon dilation for the management of bile duct stones in patients 85 years of age and older. Gastrointest Endosc 2008; 68: 477-82. 
15. Hui CK, Liu CL, Lai KC, et al. Outcome of emergency ERCP for acute cholangitis in patients 90 years of age and older. Aliment Pharmacol Ther 2004; 19: 1153-8.

16. Mitchell RM, O'Connor F, Dickey W. Endoscopic retrograde cholangiopancreatography is safe and effective in patients 90 years of age and older. J Clin Gastroenterol 2003; 36: 72-4.

17. Fritz E, Kirchgatterer A, Hubner D, et al. ERCP is safe and effective in patients 80 years of age and older compared with younger patients. Gastrointest Endosc 2006; 64: 899-905.

18. Köklü S, Parlak E, Yüksel O, Şahin B. Endoscopic retrograde cholangiopancreatography in the elderly: a prospective and comparative study. Age and Ageing 2005; 34: 572-7.

19. Chong VH, Yim HB, Lim CC. Endoscopic retrograde cholangiopancreatography in the elderly: outcomes, safety and complications. Singapore Med J 2005; 46: 621-6.

20. MacMahon M, Walsh TN, Brennan P, et al. Endoscopic retrograde cholangiopancreatography in the elderly: a single unit audit. Gerontology 1993; 39: 28-32.

Received: 9.10 .2013

Accepted: 1.05 .2014 